\title{
Novel catalysts for valorization of biomass to value-added chemicals and fuels
}

\author{
NISHITA LUCAS, NARASIMHA RAO KANNA, ATUL S NAGPURE, GANESH KOKATE \\ and SATYANARAYANA CHILUKURI* \\ Catalysis Division, National Chemical Laboratory, Dr Homi Bhabha Road, Pune 411 008, India \\ e-mail: sv.chilukuri@ncl.res.in
}

MS received 15 July 2013; revised 27 October 2013; accepted 18 November 2013

\begin{abstract}
Key furan compounds such as 5-hydroxymethylfurfural (HMF), 2,5-furandicarboxylic acid (FDCA) and 2,5-dimethylfuran (DMF) were synthesized from renewable feedstocks. Dehydration of fructose was carried out in biphasic conditions employing several solid acid catalysts by targeting selective formation of HMF. Its selectivity is linearly dependent on total acidity clearly revealing that lower acidity favours selective formation of HMF. Oxidation and hydrogenolysis of HMF has been explored using 2 wt $\%$ Ru-K-OMS-2. The catalysts used for each transformation were subjected to detailed characterization using XRD, BET surface area, temperature-programmed desorption and transmission electron microscopy. The effect of various reaction parameters was also investigated for obtaining high yields of desired chemical intermediates. High FDCA yields of $93.4 \mathrm{~mol} \%$ and $66 \mathrm{~mol} \%$ were achieved in alkaline and base-free conditions, respectively. The $2 \mathrm{wt} \% \mathrm{Ru}-\mathrm{K}-\mathrm{OMS}-2$ is a versatile catalyst as it also catalyses HMF hydrogenolysis giving $33 \mathrm{~mol} \%$ of DMF. Thus, utility of various novel materials as catalysts has been demonstrated in the multistep transformations of hexoses to furan-based fuels and chemicals.
\end{abstract}

Keywords. Fructose; dehydration; 5-hydroxymethyl furfural; 2,5-dimethylfuran; 2,5-furan dicarboxylic acid.

\section{Introduction}

Dwindling reserves of fossil fuels calls for the development of novel, renewable, environment-friendly chemicals and fuel sources. In this context, effective utilization of biomass for the production of fuels and chemicals has emerged as an important area of research. Saccharides have attracted greater attention as a promising carbon-based alternative source as it is a renewable chemical feedstock. ${ }^{1,2}$ Hexoses are carbohydrates which are most abundant monosaccharides found in nature. Hence, their conversion to useful chemicals has been intensely explored. ${ }^{3}$ Catalytic transformation of hexoses into furans is highly interesting and challenging, as it is a multistep process including dehydration, hydrolysis, isomerization, reforming, aldol condensation, hydrogenation, oxidation etc. Among the various furanic compounds involved in this strategy; 5-hydroxymethylfurfural (5-HMF), 2,5furandicarboxylic acid (FDCA) and 2,5-dimethylfuran (DMF) are highly important compounds as they can be used as starting materials for new products as well as replacement of oil-derived chemicals.

*For correspondence
Synthesis of HMF through dehydration of hexoses is extensively studied due to importance of HMF as a platform chemical. ${ }^{4}$ Potential applications of HMF includes its selective oxidation to FDCA, ${ }^{5,6}$ hydrogenolysis to $\mathrm{DMF}{ }^{7}$ reduction to 2,5-bishydroxymethylfuran and 2,5-bis(hydroxymethyl)tetrahydrofuran. ${ }^{8,9}$

The latter can serve as alcohol components in the production of polyesters. Levulinic acid, a product obtained by rehydration of HMF, is an important chemical building block with versatile applications. ${ }^{10,11}$ Moreover, numerous phenolic resins and polymerizable furanic compounds with promising properties have been prepared from HMF. ${ }^{12,13}$ As a result of the above described versatile applications, successful efforts were made to produce HMF using a variety of reaction systems, for e.g., ionic liquids, ${ }^{14,15}$ high boiling organic solvents such as dimethylsulphoxide, ${ }^{16,17}$ water $^{18}$ and biphasic systems, ${ }^{19,20}$ using both homogeneous and heterogeneous catalysts. Ionic liquid-based systems have emerged as excellent medium for selective formation of HMF but suffer drawbacks such as mass transfer limitations and high cost. Reactions in water medium offer a green protocol for HMF preparation, but HMF yields are lower as rehydration to LA is favourable; whereas, in DMSO, formation of LA is suppressed 
leading to high yields of HMF. However, this approach necessitates difficult and energy intensive product isolation procedures. ${ }^{19}$ In this context, biphasic systems are superior in terms of high HMF yields and energy efficiency.

In chemical conversion process, compounds such as HMF, FDCA and DMF are interrelated by reaction network. Indeed FDCA has been found to be useful as corrosion inhibitor, fungicide and melting agent for foundry sands as well as intermediate in pharmaceutical and photography fields. ${ }^{20,21}$ It has also gained interest as a monomer of new polymeric materials for special applications. ${ }^{22,23}$ Additionally, it has large potential as a replacement to terephthalic acid, a widely used component in various polyesters such as polyethylene terephalate (PET) and polybutyleneterephthalate (PBT). ${ }^{24-26}$ It can also serve as starting material for the production of succinic acid whose consumption rate is large enough. Thus, the potential of FDCA is visible and it is identified as one of the 12 building block compounds that can be produced from sugars via biological or chemical processes. ${ }^{27}$ Several heterogeneous catalysts have been explored for the synthesis of FDCA in alkaline conditions ${ }^{28,29}$ and in base-free conditions ${ }^{30}$ using molecular oxygen as oxidant. Researchers have used metal-supported catalysts for the conversion of HMF to FDCA. ${ }^{31,32}$ Since the above reaction is base-promoted; there is need to choose support that has basic properties. In this context, a basic support namely K-OMS-2 (Kexchanged octahedral molecular sieve-2) was chosen, exchanged with $\mathrm{Ru}$ and explored for HMF oxidation.

DMF obtained through hydrogenolysis of HMF is a good candidate as a sustainable liquid fuel. Compared to bioethanol, DMF has 30\% higher energy density than ethanol $\left(23 \mathrm{MJL}^{-1}\right)$ and also has high research octane number $(\mathrm{RON}=119) .{ }^{33}$ Moreover, DMF is immiscible in water and easier to blend with gasoline. It has been successfully tested as a biofuel in a single-cylinder gasoline direct-injection (GDI) research engine. ${ }^{34}$ The performance of DMF was satisfactory against gasoline in terms of combustion, ignition and emission characteristics. Several attempts have been made to synthesize DMF. Nobel metals supported on carbon as well as basic supports such as hydrotalcites favour selective formation of DMF. ${ }^{35,36}$ Visualizing this aspect, the above-mentioned Ru exchanged K-OMS-2 was screened for synthesis of DMF.

Thus, the present study describes selective dehydration of sugars to HMF, in biphasic systems using solid acid catalysts. Further, transformation of HMF to FDCA by selective oxidation and its hydrogenolysis to DMF are also investigated by Ru supported on K-OMS2. For each transformation, the synthesized materials were subjected to detailed characterization to understand the relationship between reactivity and selectivity during reaction. Various process parameters were also optimized aiming for higher yields of targeted furan compounds.

\section{Experimental}

\subsection{Materials}

Fructose, methyl isobutyl ketone (MIBK), $25 \% \mathrm{NH}_{3}$ solution, zirconium oxychloride $\left(\mathrm{ZrOCl}_{2} .8 \mathrm{H}_{2} \mathrm{O}\right)$, dodecatungstophosphoric acid (TPA), orthophosphoric acid, aluminium sulphate, 1-butanol, sodium borohydride, ammonium nitrate were purchased from Loba Chemie Pvt. Ltd., aluminuim chloride, tetraethyl orthosilicate (TEOS) and poly(ethylene glycol)-blockpoly(propylene glycol)-block-poly(ethylene glycol) (average molecular weight, 5800), triethylamine, hexamethyleneimine, pseudobohemite, HMF, DMF, 2,5dimethyltetrahydrofuran, 2-methyltetrahydrofuran and FDCA were procured from Sigma-Aldrich. 2Methylfuran was purchased from Alfa Aesar. Sodium hydroxide was procured from SD Fine Chemicals and sodium silicate $\left(60 \% \quad \mathrm{SiO}_{2}, 18 \% \quad \mathrm{Na}_{2} \mathrm{O}\right)$ was purchased from Riedel-deHaen. All the chemicals were of research grade and were used after drying following standard procedures. Zeolites $\mathrm{NH}_{4}^{+}$mordenite $(\mathrm{Si} / \mathrm{Al}=10)$ and $\mathrm{NH}_{4}^{+}$-beta were $(\mathrm{Si} / \mathrm{Al}=19)$ obtained from Zeolyst International, USA. $\mathrm{NH}_{4}^{+}$-ZSM5 $(\mathrm{Si} / \mathrm{Al}=28)$ was obtained from catalysts pilot plant, National Chemical Laboratory, India. All the zeolites were calcined at $450^{\circ} \mathrm{C}$ for $4 \mathrm{~h}$ in air before using.

\subsection{Catalyst preparation}

2.2a Synthesis of AlPO-5 and SAPO-5: The $\mathrm{AlPO}_{4}-5$ and SAPO-5 molecular sieves were synthesized as per reported procedures. ${ }^{37,38}$ In a typical $\mathrm{AlPO}_{4}-5$ synthesis; $5.51 \mathrm{~g}$ of pseudoboehmite was added to dilute phosphoric acid (9.22 $\mathrm{g}$ of $\mathrm{H}_{3} \mathrm{PO}_{4}$ in $55 \mathrm{~g}$ of water) slowly under stirring. After the addition of aluminium source, stirring was continued for $30 \mathrm{~min}$. To this mixture, $4.73 \mathrm{~g}$ of triethylamine was added under vigorous stirring. The gel thus obtained was autoclaved at $180^{\circ} \mathrm{C}$ for $24 \mathrm{~h}$ under autogeneous pressure without any stirring. The crystalline product obtained was filtered and washed with double distilled water. The crystals were dried for $12 \mathrm{~h}$ at $110^{\circ} \mathrm{C}$ and the template was removed by heating the sample in air at $550^{\circ} \mathrm{C}$ for $12 \mathrm{~h}$. In case of SAPO5 , synthesis procedure remained the same, except that required fumed silica was added to the gel followed by triethylamine addition. 
2.2b Synthesis of H-MCM-22: The catalyst AlMCM-22 ( $\mathrm{Si} / \mathrm{Al}=15)$ with MWW topology was prepared by hydrothermal synthesis according to the procedure given in literature. ${ }^{39}$ The crystalline product was dried at $120^{\circ} \mathrm{C}$ for $10 \mathrm{~h}$ and subsequently calcined in air at $550^{\circ} \mathrm{C}$ for $7 \mathrm{~h}$. The calcined materials were ion-

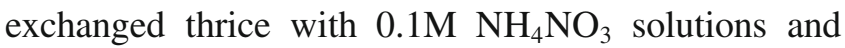
then dried overnight at $110^{\circ} \mathrm{C}$. They were calcined in air at $450^{\circ} \mathrm{C}$ for $3 \mathrm{~h}$ prior to their catalytic evaluation.

\section{2c Synthesis of AlSBA-15: The support SBA-15} was prepared using procedure reported by Stucky and coworkers. ${ }^{40}$ AlSBA-15 was prepared by post-synthesis method in which anhydrous $\mathrm{AlCl}_{3}$ was dissolved in dry ethanol $(25 \mathrm{~mL})$. To this solution, SBA-15 (1 g) was added and refluxed for $10 \mathrm{~h}$ under stirring. The material was then filtered, washed repeatedly with dry ethanol and dried at room temperature followed by calcination at $550^{\circ} \mathrm{C}$ for $5 \mathrm{~h}$ to get Al-SBA15 catalyst.

2.2d Synthesis of 15 wt\% TPA on $\mathrm{ZrO}_{2}$ : This catalyst was prepared by wet impregnation following the procedure described elsewhere. ${ }^{41}$ The support zirconium oxyhydroxide was prepared by adding $5 \mathrm{wt} \% \mathrm{NH}_{3}$ solution to $0.5 \mathrm{M}$ solution of $\mathrm{ZrOCl}_{2} .8 \mathrm{H}_{2} \mathrm{O}$, dropwise under continuous stirring till a final $\mathrm{pH}$ of 9.5 was reached. The precipitate was filtered, washed repeatedly (till free from chloride ions), dried at $110^{\circ} \mathrm{C}$ for $14 \mathrm{~h}$ and crushed to obtain white zirconium oxyhydroxide powder. To methanolic solution of TPA, zirconium oxyhydroxide was added and stirred for $12 \mathrm{~h}$ at room temperature. The solvent was evaporated to dryness, dried at $80^{\circ} \mathrm{C}$ overnight and calcined at $750^{\circ} \mathrm{C}$ to get $15 \mathrm{wt} \%$ $\mathrm{TPA} / \mathrm{ZrO}_{2-} 750$ (hereafter 15TZ750).

2.2e Synthesis of $2 w t \%$ Ru-K-OMS-2: Support KOMS-2 material was prepared by procedure described in literature. ${ }^{42}$ Ruthenium-exchanged K-OMS-2 was prepared by ion exchange. In a typical synthesis, $2 \mathrm{~g}$ of K-OMS-2 was dispersed in $20 \mathrm{~mL}$ of distilled water along with $8 \mathrm{~mL}$ of ruthenium chloride solution $(\mathrm{Ru}$ content is $5 \mathrm{mg} / \mathrm{mL}$ ), the above mixture was stirred for $3 \mathrm{~h}$ at $80^{\circ} \mathrm{C}$. The sample was then filtered, washed thoroughly using deionised water and dried in oven at $100^{\circ} \mathrm{C}$ for $10 \mathrm{~h}$. Ion exchange material was reduced by excess $\mathrm{NaBH}_{4}$, in ethanol solution followed by drying in an oven at $100^{\circ} \mathrm{C}$ for $10 \mathrm{~h}$. Ruthenium content of the sample was estimated using ICP-OES (Spectro Arcos).

\subsection{Characterization}

Specific surface area of the catalysts was measured by $\mathrm{N}_{2}$ physisorption at liquid nitrogen temperature using Quantachrome Autosorb IQ. Samples were degassed at $200^{\circ} \mathrm{C}$ in vacuum for $4 \mathrm{~h}$ before $\mathrm{N}_{2}$ physisorption measurements. Surface area of the material was calculated by BET and t-plot methods. Pore volumes were calculated using De Boer's t-plot method. ${ }^{43}$

Wide angle powder XRD patterns were collected using PANalytical X'Pro dual goniometer diffractometer equipped with an $\mathrm{X}$ 'celator solid state detector. Nifiltered $\mathrm{Cu} \mathrm{K} \alpha(\lambda=1.5406 \AA, 40 \mathrm{kV}, 30 \mathrm{~mA})$ radiation was used and data collection was carried out using a flat holder in Bragg-Brentano geometry. Data was recorded in $2 \theta$ range of $10-90^{\circ}$ with $0.02^{\circ}$ step size. Low-angle $X$-ray diffraction patterns were collected in the $2 \theta$ range of $0.5-5^{\circ}$, with the above instrument at a scan rate of $0.5^{\circ} \mathrm{min}^{-1}$.

Acidity of the catalysts was investigated by temperature-programmed desorption of $\mathrm{NH}_{3}\left(\mathrm{NH}_{3}-\right.$ TPD) using a Micromeritics Autochem-2920 instrument. Prior to TPD run, the sample was activated at $450^{\circ} \mathrm{C}$ in He flow $\left(40 \mathrm{~mL} \mathrm{~min}^{-1}\right)$ for $1 \mathrm{~h}$. Subsequently, the temperature was brought down to $80^{\circ} \mathrm{C}$ and $\mathrm{NH}_{3}$ was sorbed by exposing the samples to a stream of $10 \% \mathrm{NH}_{3}$ in $\mathrm{He}\left(30 \mathrm{~mL} \mathrm{~min}{ }^{-1}\right)$ for $0.5 \mathrm{~h}$. Temperature was then raised to $100^{\circ} \mathrm{C}$ and flushed with $\mathrm{He}$ for $1 \mathrm{~h}$ at $100^{\circ} \mathrm{C}$ to remove the physisorbed $\mathrm{NH}_{3}$. Desorption of $\mathrm{NH}_{3}$ was carried out in He flow $\left(40 \mathrm{~mL} \mathrm{~min}{ }^{-1}\right)$ by increasing the temperature to $550^{\circ} \mathrm{C}$ at $10^{\circ} \mathrm{C} \mathrm{min}-1$, while monitoring the concentration of $\mathrm{NH}_{3}$ desorbed using a thermal conductivity detector.

Transmission electron microscopy of $2 \mathrm{wt} \% \mathrm{Ru}-\mathrm{K}-$ OMS-2 was carried out using FEI Technai TF-30 instrument operating at $300 \mathrm{kV}$. Samples for TEM measurements were prepared by placing a droplet of the sample suspension, prepared in isopropyl alcohol using ultrasonification on a carbon-coated copper grid by leaving them for drying at room temperature.

\subsection{Catalytic activity}

Dehydration reaction was carried out in $300 \mathrm{~mL}$ Parr (SS 316) autoclave with a teflon liner. Hydrogenolysis and oxidation reactions were carried out in $100 \mathrm{~mL}$ and $50 \mathrm{~mL}$ Parr (SS 316) autoclaves, respectively. The reactants and catalyst were charged and the closed vessel was purged with nitrogen (for dehydration), hydrogen (for hydrogenolysis) and with molecular oxygen (for oxidation). The reactions were conducted at the desired temperatures and pressures. At the end of reaction, the aqueous samples were filtered using $0.22 \mu \mathrm{m}$ filter and the filtrate was analysed using HPLC, equipped with RI detector and Rezex ROA-Organic Acid $\mathrm{H}^{+}$column $(300 \times 7.8 \mathrm{~mm})$ with $5 \mathrm{mM} \mathrm{H}_{2} \mathrm{SO}_{4}$ as the mobile phase at a flow rate of $0.6 \mathrm{~mL} \mathrm{~min}{ }^{-1}$. The organic product samples 
Table 1. Textural and physiochemical properties of catalysts in dehydration of fructose to HMF.

\begin{tabular}{|c|c|c|c|c|c|c|}
\hline Catalyst & $\mathrm{Si} / \mathrm{Al}$ & $\begin{array}{c}\text { SA } \\
\left(\mathrm{m}^{2} / \mathrm{g}\right)\end{array}$ & $\mathrm{PD}(\AA)$ & $\begin{array}{l}\text { Acidity } \\
(\mathrm{mmol} / \mathrm{g})\end{array}$ & $\begin{array}{l}\text { Fructose conv. } \\
\quad(\mathrm{mol} \%)\end{array}$ & $\begin{array}{c}\text { HMF Sel. } \\
(\%)\end{array}$ \\
\hline AlPO-5 & - & 320 & 0.74 & 0.127 & 30 & 83 \\
\hline SAPO-5 & - & 330 & 0.74 & 0.78 & 71 & 42 \\
\hline SBA-15 & - & 808 & 60.5 & 0.002 & - & - \\
\hline Al-SBA15 & 19 & 549 & 53.7 & 0.267 & 66 & 62 \\
\hline H-MCM-22 & 15 & 409 & $\begin{array}{l}0.51 \times 0.55 \\
0.53 \times 0.56\end{array}$ & 1.02 & 78 & 36 \\
\hline H-ZSM5 & 28 & 360 & $\begin{array}{c}0.54 \times 0.56 \\
0.55 \times 0.51^{45}\end{array}$ & 0.58 & 70 & 47 \\
\hline H-Beta & 19 & 700 & $\begin{array}{c}5.7 \times 7.5 \\
6.5 \times 5.6^{45}\end{array}$ & 0.796 & 93 & 43 \\
\hline H-Mordenite & 10 & 490 & $\begin{array}{c}6.5 \times 7.0 \\
2.6 \times 5.7^{45}\end{array}$ & 1.380 & 82 & 53 \\
\hline $15 \mathrm{TZ750}$ & - & 53 & - & 0.290 & 84 & 28 \\
\hline
\end{tabular}

Reaction conditions: Fructose $=1 \mathrm{~g}$ (in $10 \mathrm{~mL}$ water), temperature $=165^{\circ} \mathrm{C}$, catalyst $=0.15 \mathrm{~g}$, water: MIBK $=1: 5(\mathrm{v} / \mathrm{v})$, reaction time $=1 \mathrm{~h}$

Legend: $\mathrm{SA}=$ Surface area, $\mathrm{PD}=$ Pore diameter, Conv. $=$ Conversion, Sel. $=$ Selectivity

were analysed by Agilent 7890 gas chromatograph equipped with a flame ionization detector. Products were separated using a CP Sil $8 \mathrm{CB}$ capillary column (30 m length, $0.25 \mathrm{~mm}$ diameter) coated with a $0.25 \mathrm{~mm}$ thick stationary phase. Product identification was done with the help of GC/MS and confirmed with reference compounds, which were also used to develop calibration curves for quantitative GC analysis.

\section{Results and discussion}

\subsection{Characterization of catalysts}

3.1a Surface area: Specific surface areas of the catalysts were obtained from low-temperature nitrogen sorption isotherms; the values are depicted in table 1. Mesoporous SBA-15 shows high surface area of $808 \mathrm{~m}^{2} / \mathrm{g}$. Incorporation of aluminium in the silica framework leads to reduction in surface area which may be due to presence of extra framework species, these results are consistent with earlier findings. ${ }^{44}$ Among the microporous catalysts, the order of the surface area values is H-beta $\left(700 \mathrm{~m}^{2} \mathrm{~g}^{-1}\right), \mathrm{H}$-mordenite $\left(490 \mathrm{~m}^{2} \mathrm{~g}^{-1}\right)$, H-MCM-22 (409 $\left.\mathrm{m}^{2} \mathrm{~g}^{-1}\right)$, H-ZSM-5 $\left(360 \mathrm{~m}^{2} \mathrm{~g}^{-1}\right)$, SAPO-5 $\left(330 \mathrm{~m}^{2} \mathrm{~g}^{-1}\right)$, and $\mathrm{AlPO}_{4}-5\left(320 \mathrm{~m}^{2} \mathrm{~g}^{-1}\right)$. These materials due to their porous nature exhibited high surface areas. On the other hand, 15TZ750 has lowest surface area of $53 \mathrm{~m}^{2} \mathrm{~g}^{-1}$, owing to its nonporous nature.

Specific surface area values of K-OMS-2 and 2\% RuK-OMS-2 are given in table 2. The support K-OMS-2 has surface area of $97.5 \mathrm{~m}^{2} \mathrm{~g}^{-1}$, which has increased to $109.6 \mathrm{~m}^{2} \mathrm{~g}^{-1}$ on exchanging with $\mathrm{Ru}$. This increase in surface area may be due to replacement of exchangeable $\mathrm{K}^{+}$ions with larger $\mathrm{Ru}$ (undoped) compared to the parent metal oxide. However, internal surface area of the exchanged material has decreased due to the

Table 2. Textural and physiochemical properties of $2 \mathrm{wt} \% \mathrm{Ru}-\mathrm{K}-\mathrm{OMS}-2$.

\begin{tabular}{|c|c|c|c|c|c|c|}
\hline \multirow[b]{2}{*}{ Catalyst } & \multicolumn{3}{|c|}{$\mathrm{SA}\left(\mathrm{m}^{2} / \mathrm{g}\right)$} & \multirow[b]{2}{*}{$\operatorname{APD}(\AA)$} & \multirow{2}{*}{$\begin{array}{c}\text { Micropore } \\
\text { volume }^{\#}(\mathrm{cc} / \mathrm{g})\end{array}$} & \multirow[t]{2}{*}{ TPV* $(\mathrm{cc} / \mathrm{g})$} \\
\hline & $\overline{\mathrm{BET}}$ & External $^{\#}$ & Internal $^{\#}$ & & & \\
\hline K-OMS-2 & 97.5 & 80.8 & 16.6 & 68.8 & 0.0069 & 0.16 \\
\hline 2 wt $\%-R u-K-O M S-2$ & 109.6 & 107.1 & 2.52 & 32.6 & 0.0004 & 0.17 \\
\hline
\end{tabular}

*TPV for pores with diameter less than $205 \AA$ at $P / P_{0}=0.9$

\# Estimated from t-method

Legend: $\mathrm{SA}=$ Surface Area, $\mathrm{APD}=$ Average pore diameter, $\mathrm{TPV}=$ Total pore volume 
replacement of potassium by heavier Ru leading to the partial blockage of pores. This also accounts for reduction in average pore diameter and total pore volume of the exchanged sample.

3.1b X-ray diffraction: Structural aspects of the catalysts used for dehydration reactions was determined by powder and X-ray diffraction and depicted in figure 1a. The X-ray powder diffraction patterns of H-beta, H-mordenite, H-ZSM5 and H-MCM-22 are in agreement with the patterns typically found for these zeolites in literature. ${ }^{45}$ Microporous aluminophosphate SAPO-5 sample showed X-ray diffraction patterns corresponding to that of the AFI topology reported previously. ${ }^{46}$ Additionally, peak intensity of the XRD patterns was retained implying that incorporation of $\mathrm{Si}$ into the framework had no profound effect on the crystallinity of the samples. The XRD patterns of mesoporous SBA-15 and AlSBA-15 samples are shown in figure $1 \mathrm{~b}$. These consist of three well-resolved peaks in the $2 \theta$ range of $0.8-1.8^{\circ}$, which are similar to those recorded for SBA-15 in literature. ${ }^{40}$ The presence of one strong reflection of (100) plane at $2 \theta=0.8$ and two weaker reflections of (110), (200) at higher $2 \theta$ are associated with the p6mm hexagonal symmetry in the materials. Similarity in XRD patterns of AlSBA15 and SBA-15 clearly shows that no perturbation of the hexagonal mesoporous structure occurred after modification. Figure 1a (inset) shows the XRD patterns of $15 \mathrm{TZ} 750$ which are predominantly in the tetragonal phase. Pure zirconia calcined at high temperature mainly exists in monoclinic phase with very little tetragonal phase. ${ }^{47}$ Addition of the surface species results in stabilization of the tetragonal phase of zirconia. Additionally, peaks were obtained in $2 \theta=22-25^{\circ}$ region revealing decomposition of heteropoly acid at higher temperatures.

Structure of K-OMS-2 and $2 \% \mathrm{Ru}-\mathrm{K}-\mathrm{OMS}-2$ is depicted in figure 1c. Diffraction pattern of K-OMS-2 shows the presence of (110), (200), (310), (211) planes which are typical of cryptomelane structure, ${ }^{48}$ which are retained after Ru exchange. In fact, the XRD peaks are sharper after $\mathrm{Ru}$ exchange, showing better crystallinity. This has also resulted in increase of surface area of the sample. Additionally, no peaks of $\mathrm{Ru}_{2} \mathrm{O}_{3}$ were observed in the XRD.

3.1c TPD of $\mathrm{NH}_{3}:$ Acidity of the catalysts employed for dehydration reaction was determined by TPD of $\mathrm{NH}_{3}$. Total acidity of materials is expressed in mmol $\mathrm{g}^{-1}$ of desorbed $\mathrm{NH}_{3}$ and these values are listed in table 1. Among the catalysts, zeolites were highly
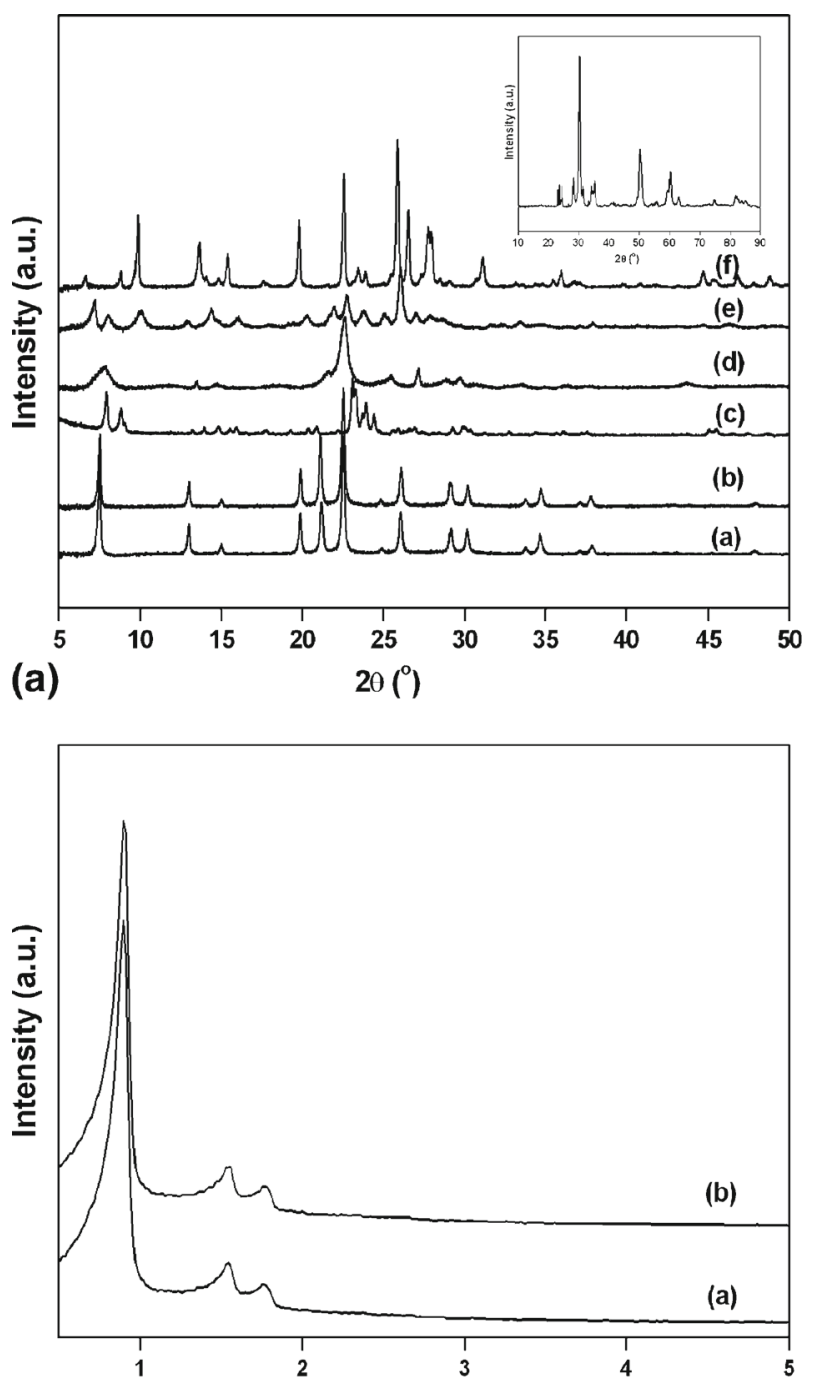

(b)

$\left.201^{\circ}\right)$

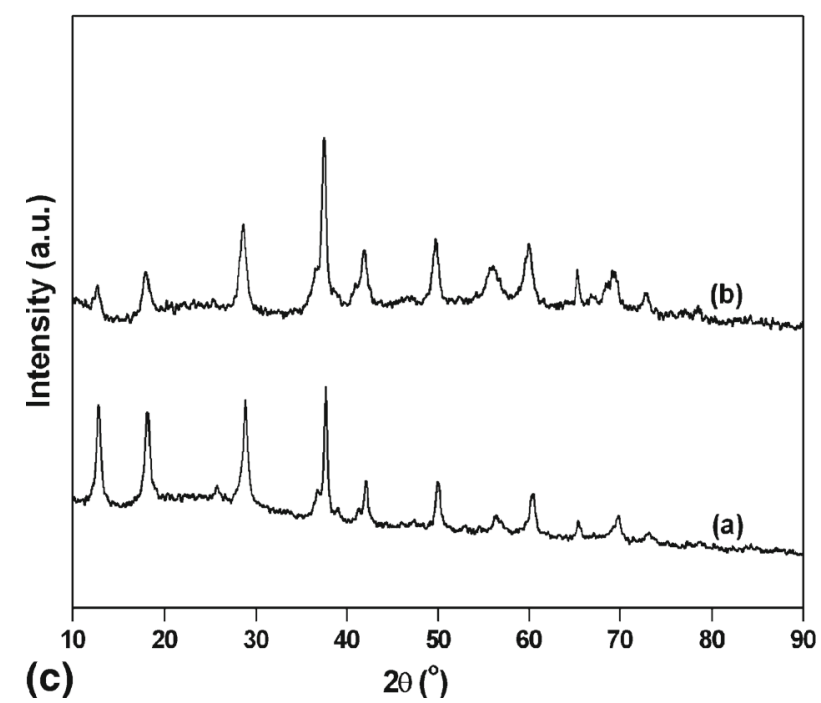

Figure 1. (a) X-ray diffractograms of (a) AlPO-5, (b) SAPO-5, (c) H-ZSM-5, (d) H-beta, (e) H-MCM-22 and (f) $\mathrm{H}$-mordenite (inset) 15TZ750. (b) X-ray diffractograms of (a) SBA-15 and (b) AlSBA-15. (c) X-ray diffractograms of (a) K-OMS-2 and (b) $2 \mathrm{wt} \% \mathrm{Ru}-\mathrm{K}-\mathrm{OMS}-2$. 
acidic and their acidity can be ranked as H-Mordenite $(1.38 \mathrm{mmol} / \mathrm{g})>\mathrm{H}-\mathrm{MCM}-22(1.020 \mathrm{mmol} / \mathrm{g})>\mathrm{H}-$ Beta $(0.796 \mathrm{mmol} / \mathrm{g})>\mathrm{H}-\mathrm{ZSM}-5(0.579 \mathrm{mmol} / \mathrm{g})$. There is an increase in acidity with decreasing $\mathrm{Si} / \mathrm{Al}$ ratio. For aluminophosphate samples, SAPO5 has higher acidity $(0.78 \mathrm{mmol} / \mathrm{g})$ than $\mathrm{AlPO}_{4}$ $5(0.147 \mathrm{mmol} / \mathrm{g})$ as framework $\mathrm{P}(\mathrm{V})$ is replaced by $\mathrm{Si}$ (IV), imparting a net negative charge to the framework. ${ }^{49}$ On the other hand, the acidity in $\mathrm{AlPO}_{4}$ 5 is attributed to very weak acidity due to presence of P-OH groups. Mesoporous SBA-15 has very weak acidity $(0.002 \mathrm{mmol} / \mathrm{g})$ due to the presence of surface silanol groups. However, this acidity is very low as compared to aluminium-containing AlSBA-15 sample $(0.267 \mathrm{mmol} / \mathrm{g})$, suggesting the formation of acid sites on post-modification with aluminium.

3.1d TEM: The TEM images of 2 wt $\%$ Ru-K-OMS2 is shown in figure 2 . The figure shows nanoscale size fibers of the parent KOMS-2. The lattice fringes shows $\mathrm{d}$ spacing of $0.47 \mathrm{~nm}$ which corresponds to (200) plane of cryptomelane structure. The lattice fringes of Ru particle (d spacing of $0.21 \mathrm{~nm}$ ) can easily be distinguished from that of the support.

\subsection{Catalytic activity in dehydration}

Dehydration of fructose to HMF was used as a model reaction for testing catalytic activity and selectivity of various catalysts. This reaction can yield numerous products (scheme 1), but we had selectively targeted HMF. Results of the catalytic activity are given in table 1 . We have used microporous zeolites and aluminophosphates and mesoporous AlSBA-15. Under the reaction conditions employed, the zeolites with higher total acidity gave higher fructose conversion $(93,82$, 78, $70 \mathrm{~mol} \%$ for beta, mordenite, MCM-22 and ZSM-5, respectively), but resulted in lower selectivity for HMF
( $\sim 50 \%)$. Conversion depends on the acidity; high conversions are obtained for catalysts with high acidity, only exception being H-beta. Superior catalytic performance of H-beta is attributed to smaller crystallite size which facilitates easier diffusion of reactants/products, leading to higher conversion. Results of the catalytic activity of zeolites are in good agreement with the earlier findings which shows that targeted furan compounds undergo humin formation in the intrazeoloitic channels thus lowering its yield. ${ }^{50}$ For microporous aluminophosphate catalysts, SAPO-5 gave higher conversion of $71 \mathrm{~mol} \%$ than AlPO-5 (30 mol\%), due to higher acidity of the former. However, the selectivity of AlPO$5(83 \%)$ was much higher than SAPO-5 (42\%). Mesoporous AlSBA-15, was also superior to zeolites for selective formation of HMF. Conversion of $66 \mathrm{~mol} \%$ and selectivity of $62 \mathrm{~mol} \%$ is obtained for AlSBA15. This mesoporous catalyst gave maximum yield of HMF. In order to furnish insights into interplay of acidity; selectivity of HMF was plotted against total acidity. The result is shown in figure 3, HMF selectivity decreases with increasing total acidity clearly revealing that lower acidity favours selective formation of HMF. Since HMF is a highly reactive compound, it can undergo condensation reactions on acid sites with medium to strong acidity to give humins, thereby lowering its yield. Researchers demonstrated that heterocyclic compounds are strongly adsorbed on the strong acidic sites of microporous catalyst leading to their decomposition. ${ }^{51}$ This may be the probable reason for lower selectivity of zeolites and SAPO-5. Superior catalytic performance of AlSBA-15 reveals that low total acidity and mesoporosity is advantageous for selective formation of HMF from bulky reactants such as hexoses. On the other hand, when we employed 15 TZ750 (tungstated zirconia) as catalyst, which has no pore constraints, fructose conversion was $84 \mathrm{~mol} \%$ while HMF selectivity was only $28 \%$. This shows that surface acidity has to be optimum in terms of strength and type
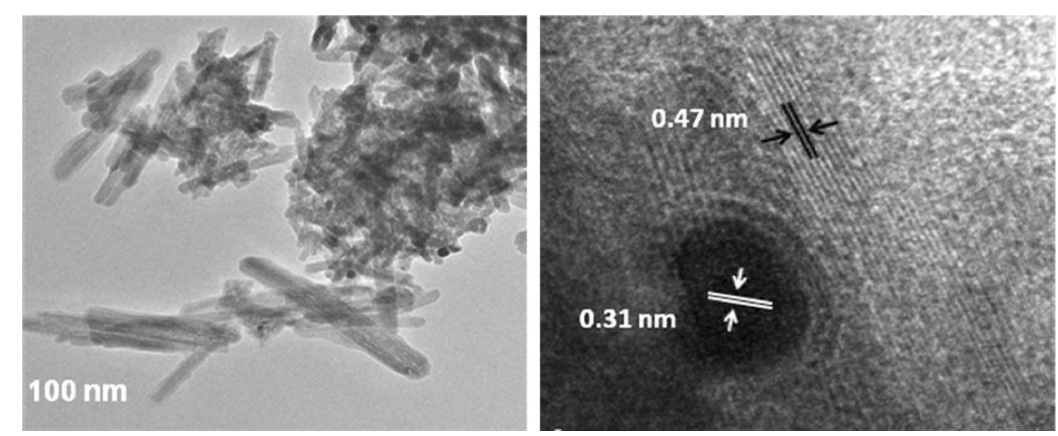

Figure 2. TEM images of $2 \mathrm{wt} \% \mathrm{Ru}-\mathrm{K}-\mathrm{OMS}-2$. 


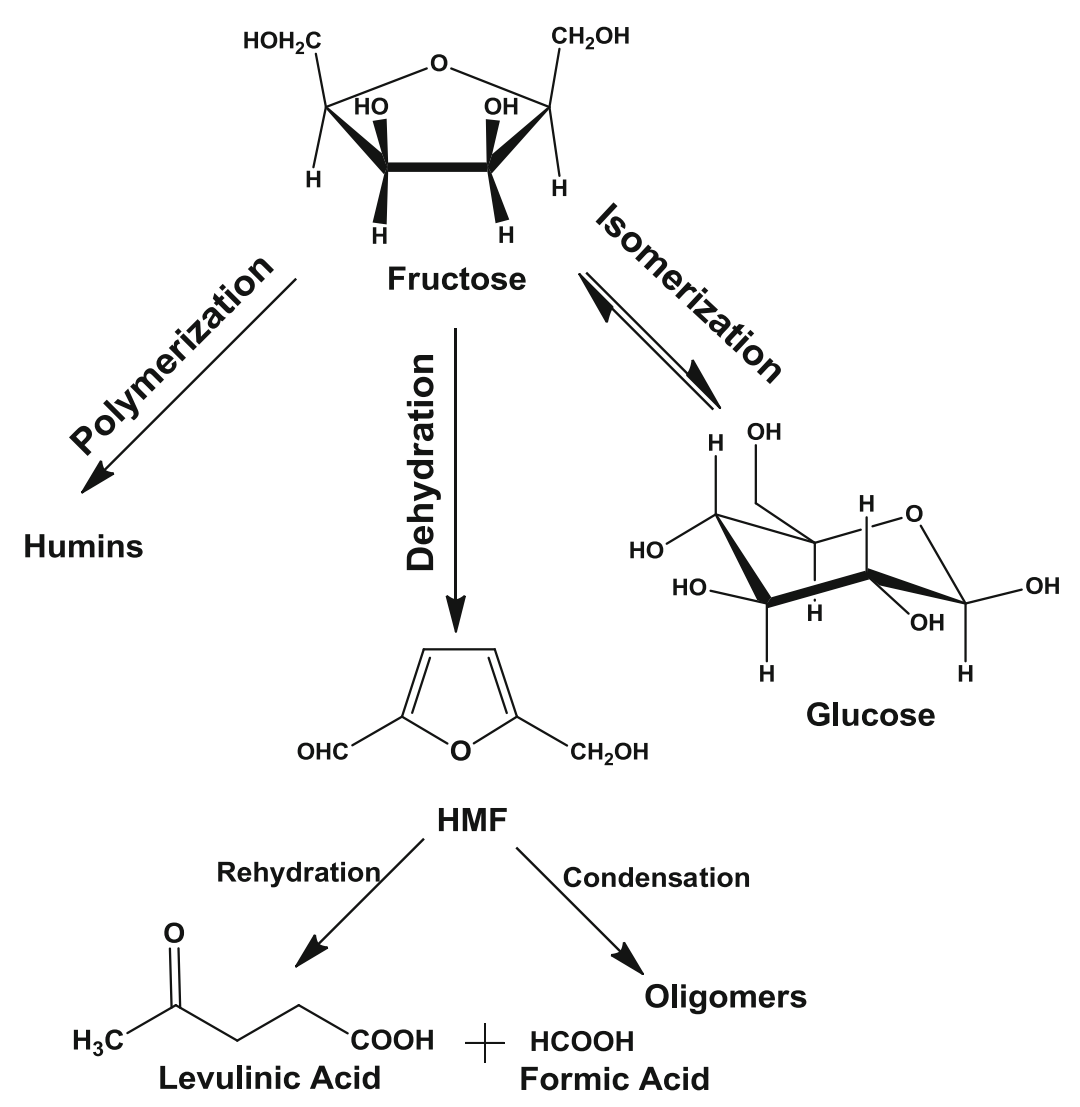

Scheme 1. Dehydration of C-6 sugars to HMF.

(Bronsted or Lewis) for attaining good HMF selectivity. Thus, it can be inferred that high acidity and probably strong acid sites does not favour selective formation of HMF under the reaction conditions employed. Presence of low acidity is vital for HMF formation which is an important finding as it will be helpful for synthesizing new catalyst systems which aim a higher yields of HMF.

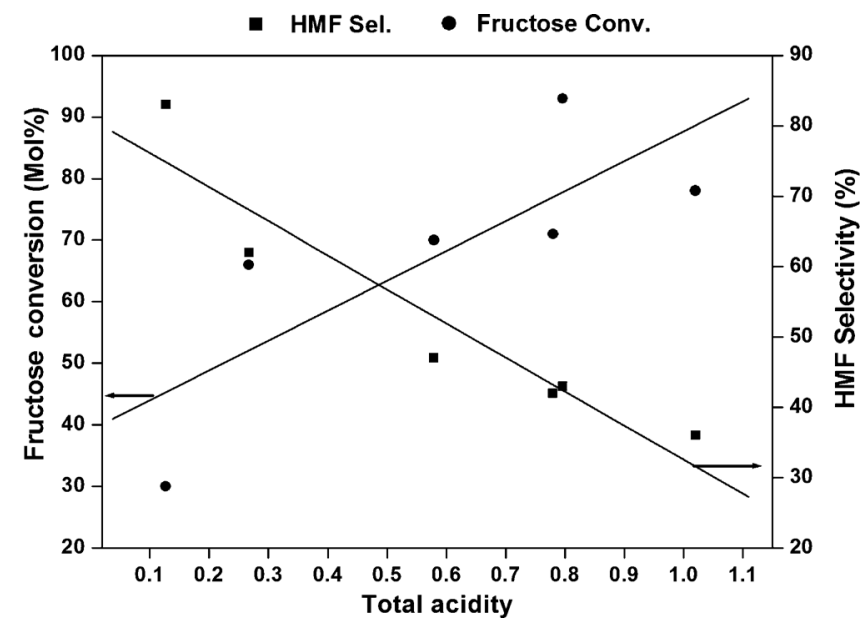

Figure 3. Fructose conversion and HMF selectivity vs. total acidity.

\subsection{Catalytic activity in oxidation of HMF to FDCA}

Selective oxidation of HMF to FDCA by using KOMS2 family of catalysts is being reported for the first time. Liquid phase oxidation of HMF to FDCA reaction was studied on 2 wt $\%$ Ru-K-OMS-2, by varying the reaction temperatures in the range of $90-120^{\circ} \mathrm{C}$. Results are shown in figure 4 with time on stream. There is no significant effect of temperature on HMF conversion as it is always close to $100 \%$ after $2 \mathrm{~h}^{30}$ As the temperature is increased from $90^{\circ}$ to $120^{\circ} \mathrm{C}$, an increase in FDCA yield was observed, which reached maximum after a certain duration on stream at each temperature. However, further increase in reaction time led to a decrease in FDCA yield because of the condensation of acid (FDCA) and alcohol (HMFCA), catalysed by acidic $\mathrm{Mn}^{4+}$ ion (scheme 2). Initial product in the reaction is HMFCA which further oxidizes to the FFCA and finally to FDCA. The time taken to convert HMF to HMFCA is not significant, but the time required to convert HMFCA to FDCA is higher. So, oxidative conversion of HMFCA to FDCA was found to be the rate determining step in this reaction sequence.

Effect of catalyst amount on HMF oxidation was investigated and results are given in figure 5. Increase in catalyst weight has profound effect on FDCA yield 


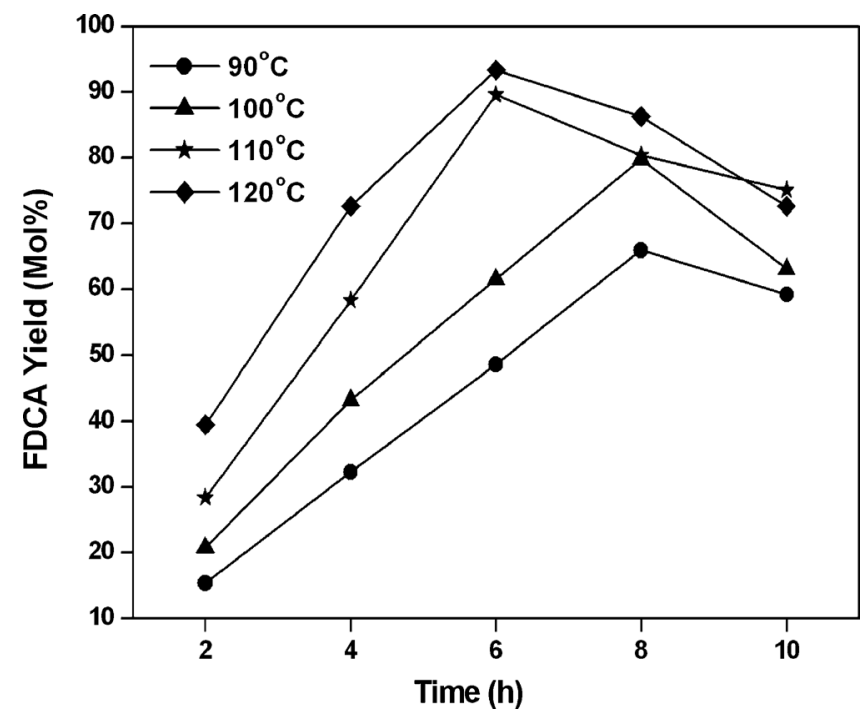

Figure 4. Effect of temperature on oxidation of HMF over $2 \mathrm{wt} \% \mathrm{Ru}-\mathrm{K}-\mathrm{OMS}-2$. Reaction conditions: $\mathrm{HMF}=0.126 \mathrm{~g}$ ( $1 \mathrm{mmol}), \mathrm{NaOH}=0.16 \mathrm{~g}(4 \mathrm{mmol})$, catalyst weight $=$ $80 \mathrm{mg}$, water $=20 \mathrm{~mL}, \mathrm{O}_{2}$ pressure $=20$ bar.

as complete conversion of HMF was observed at higher catalyst contents. With increase in catalyst amount, the time taken to achieve maximum yield has reduced. With the increase in catalyst content, more active sites are available to drive the reaction for an early completion.

The above HMF oxidation reactions are conducted in presence of added base $(\mathrm{NaOH})$ as a promoter in order to deprotonate the alcohol moiety of HMFCA to form alkoxy intermediate. ${ }^{52}$ However, aiming for a green process, reactions were conducted in base-free conditions (figure 6), which gave a maximum yield of

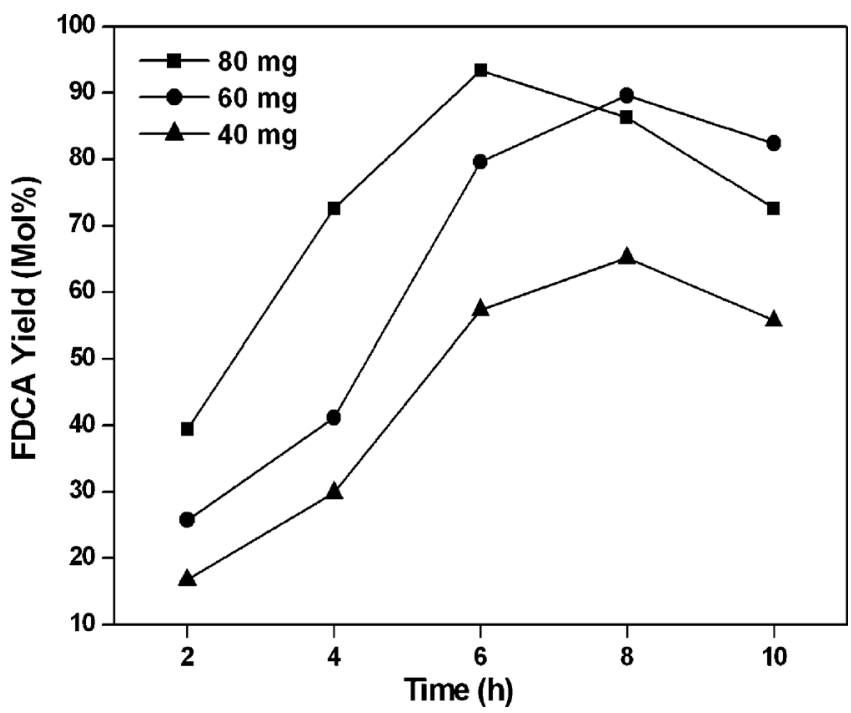

Figure 5. Effect of catalyst weight on HMF oxidation over $2 \mathrm{wt} \% \mathrm{Ru}-\mathrm{K}-\mathrm{OMS}-2$. Reaction conditions: $\mathrm{HMF}=0.126 \mathrm{~g}$ $(1 \mathrm{mmol}), \mathrm{NaOH}=0.16 \mathrm{~g}(4 \mathrm{mmol})$, temperature $=120^{\circ} \mathrm{C}$, water $=20 \mathrm{~mL}, \mathrm{O}_{2}$ pressure $=20$ bar.

66 mol\% of FDCA. So, the above catalyst can also be used without addition of external base, though it compromises FDCA yield to some extent. Further studies on base-free process of this catalyst are in progress. In order to study the effect of support; parent K-OMS-2 was also used as the catalyst. Though complete conversion of HMF was obtained on this catalyst, formation of HMFCA was observed instead of FDCA (scheme 2). Major part of the catalyst has $\mathrm{Mn}$ in +4 oxidation state. Since $\mathrm{Mn}^{4+} / \mathrm{Mn}^{3+}$ is a good redox couple, ${ }^{53}$ it drives the oxidation of much reactive aldehyde to acid to form HMFCA. However, the above redox couple potential is

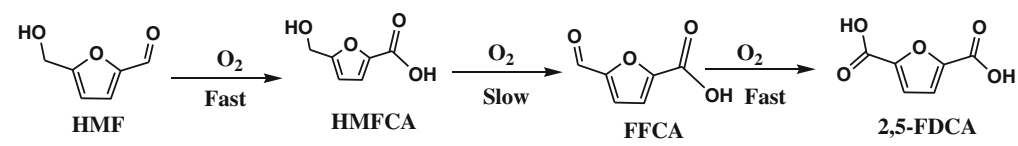

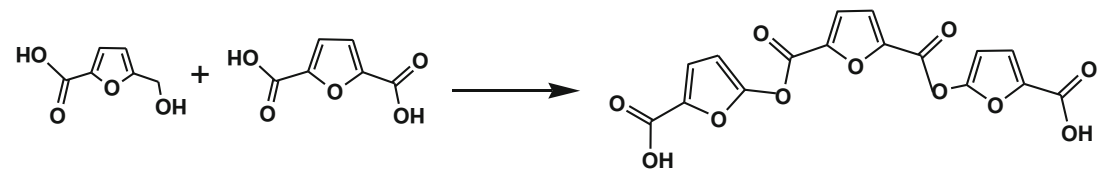

HMFCA = Hydroxymethyl furancarboxylic acid

FFCA $=$ Formyl furancarboxylic acid

Scheme 2. Oxidation of HMF to FDCA. 


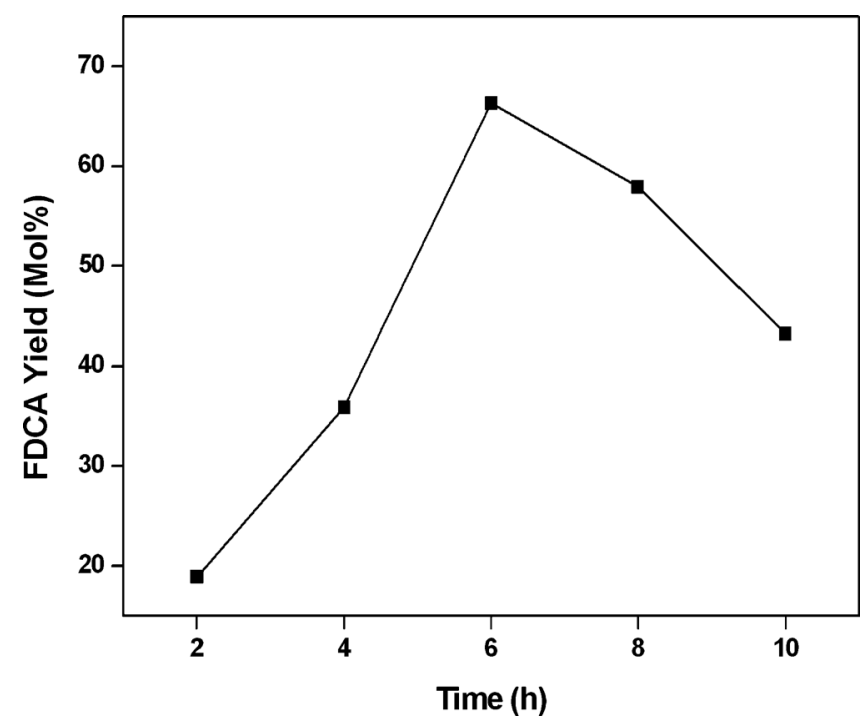

Figure 6. HMF oxidation over 2 wt $\%$ Ru-K-OMS-2 in base free conditions. Reaction conditions: $\mathrm{HMF}=0.126 \mathrm{~g}$ $(1 \mathrm{mmol})$, temperature $=120^{\circ} \mathrm{C}, \mathrm{O}_{2}$ pressure $=20$ bar.

not enough to oxidize the much less reactive alcohol group of HMF which also demonstrates the necessity of $\mathrm{Ru}$ metal.

\subsection{Catalytic activity in hydrogenolysis of $\mathrm{HMF}$ to $D M F$}

Liquid phase hydrogenolysis of HMF was studied on 2 wt\% Ru-K-OMS-2 by varying the reaction temperature in the $210-230^{\circ} \mathrm{C}$ range. With increase in temperature, there is profound effect on conversions of HMF (figure 7a). Conversion increases with time on stream, after $8 \mathrm{~h}$, it increases from 85 to $100 \mathrm{~mol} \%$ when temperature was increased from 210 to $230^{\circ} \mathrm{C}$. However, temperature also impacts DMF yields (figure $7 \mathrm{~b}$ ).$^{54}$ Yield increases with time on stream at all temperatures in $210-220^{\circ} \mathrm{C}$ range and maximum yield of $33 \mathrm{~mol} \%$ was obtained at $220^{\circ} \mathrm{C}$ after $6 \mathrm{~h}$. At lower temperature $\left(210^{\circ} \mathrm{C}\right)$, significant amount of intermediate compounds (scheme 3) such as 5-methylfurfuryl alcohol (MFA), 5-methylfurfural (MF) and 2,5-bishydroxymethylfuran (BHMF) were obtained. ${ }^{34}$ With increase in temperature and time, theses intermediates were transformed into targeted product DMF. With further increase in temperature to $230^{\circ} \mathrm{C}$, HMF conversion increases but DMF yield decreased after $6 \mathrm{~h}$ reaction time. Higher temperatures favour formation of 2,5-dimethyltetrahydrofuran (DMTHF), 2-methylfuran (MFUR) and methyl tetrahydrofuran (MTHF). Hence, $220^{\circ} \mathrm{C}$ was found to be the optimum temperature for this catalyst.
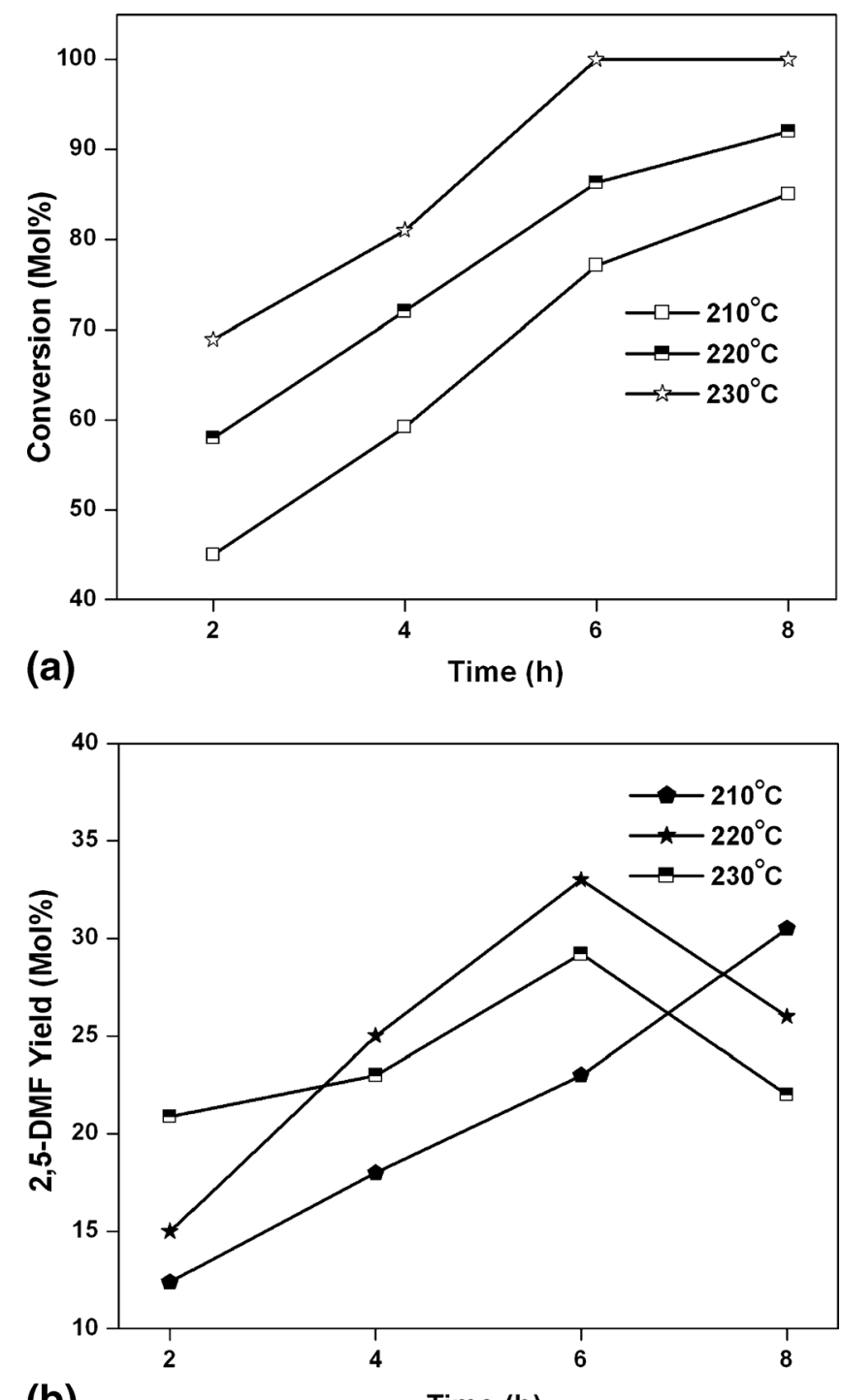

(b)

Time (h)

Figure 7. Effect of temperature on HMF hydrogenolysis over $2 \mathrm{wt} \% \mathrm{Ru}-\mathrm{K}-\mathrm{OMS}-2$. Reaction conditions: HMF = $0.126 \mathrm{~g}(1 \mathrm{mmol})$, catalyst weight $=40 \mathrm{mg}, 1$-butanol $=$ $25 \mathrm{~mL}, \mathrm{H}_{2}$ pressure $=10$ bar.

The effect of time was also investigated and results are shown in figure 8 . There are two paths in which HMF can be hydrogenated. In the first path, carbonyl group of HMF can be hydrogenated giving BHMF; and in the second, the alcohol group can be hydrogenolysed giving MF, which can be further hydrogenated to MFA. ${ }^{34}$ The first path is prominent (HMF to BHMF) compared to the second path, as it is facilitated by the basicity of catalyst leading to selective adsorption of reactant molecule through carbonyl carbon of HMF, which enhances formation of BHMF. Thus, at the beginning of the reaction, the formation of these intermediates is higher. These intermediates thus formed transform to DMF with increasing time on stream, i.e., 


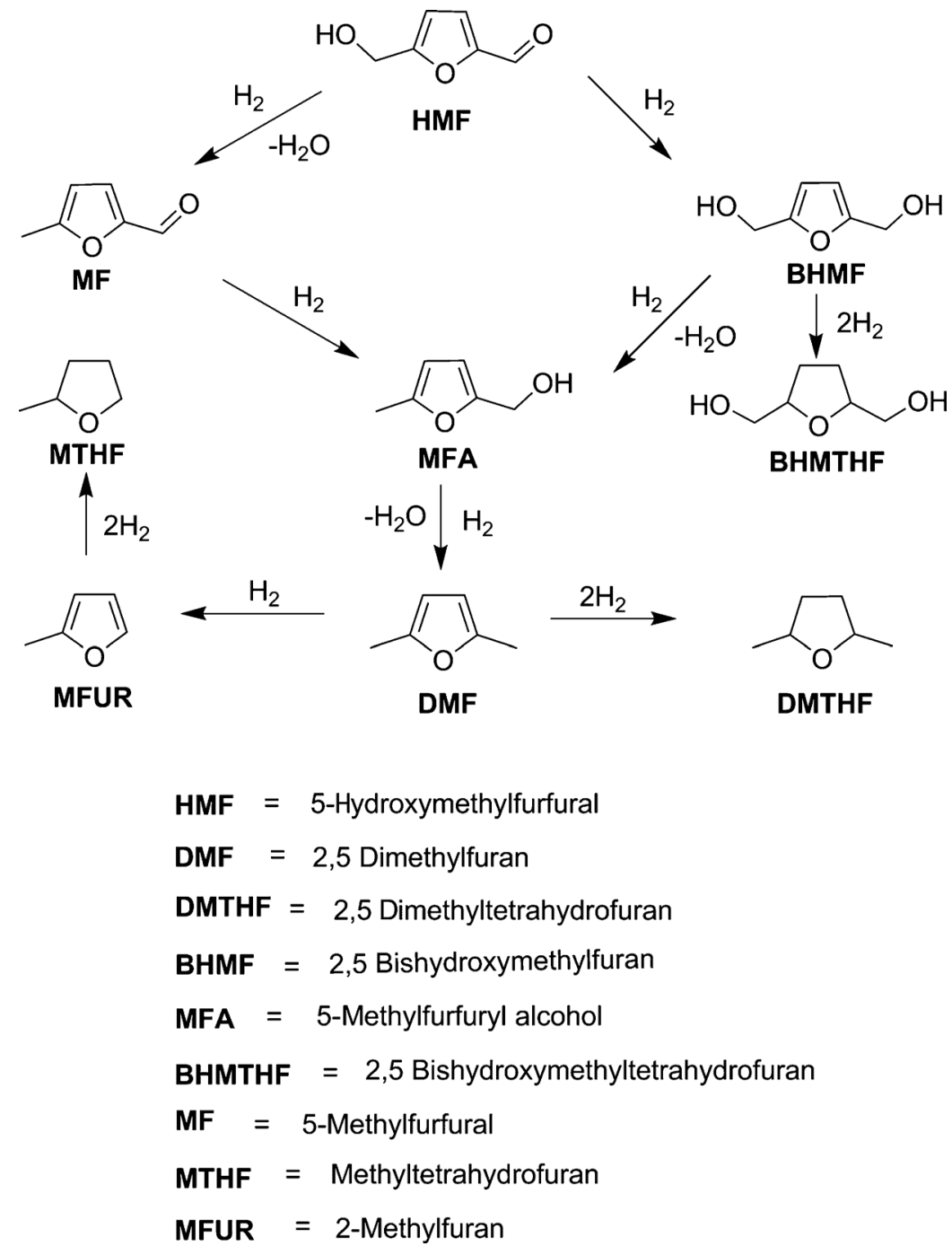

Scheme 3. Hydrogenolysis of HMF to DMF.

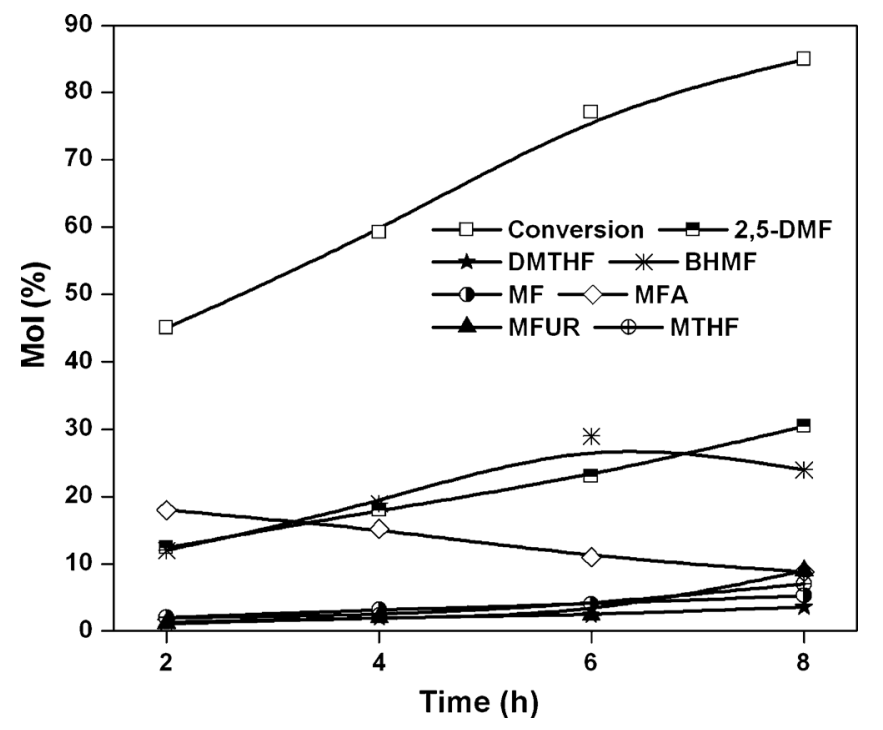

Figure 8. Effect of reaction time on HMF hydrogenolysis over $2 \mathrm{wt} \% \mathrm{Ru}-\mathrm{K}-\mathrm{OMS}-2$. Reaction conditions: HMF = $0.126 \mathrm{~g}(1 \mathrm{mmol})$, catalyst weight $=40 \mathrm{mg}$, temperature $=$ $210^{\circ} \mathrm{C}, 1$-butanol $=25 \mathrm{~mL}, \mathrm{H}_{2}$ pressure $=10$ bar. from 2 to $8 \mathrm{~h}$, thereby increasing yield from 12.4 to $30.5 \mathrm{~mol} \%$, respectively.

\section{Conclusions}

Selective formation of HMF, an important platform chemical has been studied using solid acid catalysts. A good linear correlation between the total acidity and HMF selectively was clearly seen. These findings demonstrate that the presence of optimum acidity is crucial for selective dehydration of fructose. Successful catalytic transformation of HMF to FDCA and DMF has been achieved using $2 \mathrm{wt} \%$ Ru-K-OMS-2. High FDCA yield of $93 \mathrm{~mol} \%$ and $66 \mathrm{~mol} \%$ is obtained in alkaline and base-free conditions, respectively. DMF, an important biofuel was also obtained with fairly good yield of $33 \mathrm{~mol} \%$. Thus, 2 wt $\%$ Ru-K-OMS-2 was found to be a versatile catalyst for selective oxidation and hydrogenolysis reactions. Most importantly, the 
targeted furan compounds were successfully synthesized from renewable feedstocks.

\section{Acknowledgements}

All the co-authors thank the Council of Scientific and Industrial Research (CSIR), New Delhi for providing financial support through Senior Research Fellowships. Financial support from CSIR through network project CSC-0122 is also acknowledged.

\section{References}

1. Gallezot P 2007 Green Chem. 9295

2. Lichtenthaler F W and Peters S 2004 C. R. Chim. 765

3. Corma A, Iborra S and Velty A 2007 Chem. Rev. 107 2411

4. Rosatella A, Simeonov S, Frade and Afonso C 2011 Green Chem. 13754

5. Davis S E, Houk L, Tamargo E C, Datye A K and Davis R J 2011 Catal. Today 16055

6. Gupta N K, Nishimura S, Takagaki A and Ebitani K 2011 Green Chem. 13824

7. Leshkov Y R, Barett C J, Liu Z Y and Dumesic J A 2007 Nature Lett. 447982

8. Thannatthanachon T and Rauchfuss T B 2010 Angew. Chem. Int. Ed. 496616

9. Yang W and Sen A 2010 Chem. Sus. Chem. 3597

10. Leonard R 1956 Indus. Eng. Chem. 481331

11. Ghorpade V and Hanna M 1996 US Patent 5859263.

12. Gandini A and Belcacem M N 1997 Prog. Polym. Sci. 221203

13. Koch H, Krause F, Steffan R and Woelk H U 1983 Starke 35304

14. Chan J Y and Zhang Y 2009 Chem. Sus. Chem. 2731

15. Qi X, Watanabe M, Aida T M and Smith R L 2009 Green Chem. 111327

16. Shimizu K, Uozumi R and Satsuma A 2009 Catal. Commun. 101849

17. Qi X, Watanabe M, Aida T M and Smith R L 2008 Ind. Eng. Chem. Res. 479234

18. Carlini C, Patrono P, Galleti A M and Sbrana G 2004 Appl. Catal A: Gen. 275111

19. Leshkov Y R and Dumesic J A 2009 Top. Catal. 52297

20. Leshkov Y R, Chheda J N and Dumesic J A 2006 Science 3121933

21. Christensen C H, Rass-Hansen J, Marsden C C, Taarning, E and Egeblad K 2008 Chem. Sus. Chem. 1 283

22. Kröger M, Prübe U and Vorlop K D 2000 Top. Catal. 13 237

23. Costantin M, Hamphreys T W, Lange H B, Shew D and Wagner J R 1963 US 3080279

24. Chundury D and Szmant H H 1981 Ind. Eng. Chem. Prod. Res. Dev. 20158

25. Meàlares C and Gandini A 1996 Polym. Int. 4033

26. Gandini A 2008 Macromolecules 419491
27. Werpy T and Petersen G 2004 Top value added chemicals from biomass. Available electronically at http:// www.osti.gov/bridge

28. Gorbaneb Y K, Klitgaard S K, Woodley J M, Christensen, C H and Riisager A 2009 Chem. Sus. Chem. 2672

29. Pasini P, Piccinini M, Blosi M, Bonelli R, Albonetti S, Dimitratos N, Lopez J A, Sankar M, Kiely C J, Hutchings G J and Cavani F 2011 Green Chem. 132091

30. Gupta N K, Nishimura S, Tagaki A and Ebitani K 2011 Green Chem. 13824

31. Villa A, Schiavoni M, Campisi S, Veith G M and Prati L 2013 Chem. Sus. Chem. 6609

32. Casanova O, Ibbora S and Corma A 2009 Chem. Sus. Chem. 21138

33. Barlow M T, Smith D J and Steward D G 1983 EP0082689.

34. Song S, Daniel R, Xu H, Zhang J, Turner D, Wyszynski M L and Richards P 2010 Energy Fuels 242891

35. Chidambaram M and Bell A T 2010 Green Chem. 12 1253

36. Hansen T S, Barta K, anastas P T, Ford P C and Riisager A 2012 Green Chem. 142457

37. Koskela T, Jokisaari J and Satyanarayana C 2004 Micropor. Mesopor. Mater. 67113

38. Prakash A M, Chilukuri S V V, Bagwe R P, Ashtekar S and Chakrabarty D K 1996 Micropor. Mater. 689

39. Ravisanker R, Bhattacharya D, Jacob N E and Sivsanker S 1995 Micropor. Mater. 183

40. Zhao D, Feng J, Huo Q, Melosh N, Fedrickson G, Chemlka B F and Stucky G D 1998 Science 279548

41. Devassy B M, Halligudi S B, Hegde S G, Halgeri A B and Lefebvre F 2002 Chem. Commun. 101074

42. Deguzman R N, Shen Y, Neth E J, Suib S L, Young C O, Levine S and Newsam J M 1994 Chem. Mater. 6815

43. Barrett E P, Joyner L G and Halenda P P $1951 \mathrm{~J}$. Am. Chem. Soc. 73373

44. Shanbhag G V, Joseph T and Halligudi S B $2007 \mathrm{~J}$. Catal. 250274

45. Baerlocher C, Meiser W M and Olson D H 2001 Atlas of zeolite framework types: 5th revised edition (Amsterdam: Elsevier)

46. IZA Structure Commission: http://www.iza-structure. org/databases/.

47. Bordoloi A, Mathew N T, Devassy B M, Mirajkar S P and Halligudi S B 2006 J. Mol. Catal. A: Gen. 24758

48. King' ondu C K, Opembe N, Chen C, Ngala K, Hui H, Iyer A, Hector F G and Steven L S 2011 Adv. Funct. Mater. 21312

49. Flanigen E M, Lok B M, Patton R L and Wilson S T 1988 Stud. Surf. Sci. Catal. 3913

50. Weingarten R, Tomsett J A, Conner W C and Huber G W 2011 J. Catal. 279174

51. Chica A, Strohmaier K G and Iglesia E 2005 Appl. Catal. B: Environ. 60225

52. Davis S E, Zope B N and Davis R J 2012 Green Chem. 14143

53. Serov A and Kwak C 2009 Appl. Catal. B: Environ. 90 313

54. Zhang J, Lin L and Liu S 2012 Energy Fuels 264560 